\title{
La agenda de la
}

\section{supervisión bancaria en América Latina}

\section{Ernesto Livacic}

Director,

Honorable Junta Directiva, Universidad Central,

Santiago de Chile

elivacic@123click.cl

\section{Sebastián Sáez}

\section{Consultor}

Ex Jefe del Departamento

de Estudios,

Superintendencia de

Bancos e Instituciones

Financieras de Chile

sazcabezas@entelchile.net
La reforma que los países de América Latina emprendieron durante el decenio de 1990 en el sector bancario constituyó un importante avance, pero ha resultado insuficiente. Si bien es cierto que la región en su conjunto adelantó en ella de manera significativa, particularmente en la disminución del papel del Estado; que se perfeccionaron los mecanismos de mercado y el marco regulatorio en que operaban las instituciones bancarias y que al mismo tiempo se incrementó la presencia de operadores extranjeros, no es menos cierto que, en su mayoría, los países latinoamericanos siguieron experimentando crisis sistémicas o severas inestabilidades bancarias. Esto indica que aún existen temas pendientes que deben ser abordados para contar con un sector bancario sólido en la región. Destaca entre ellos la necesidad de avanzar más hacia una mayor autonomía efectiva de los entes fiscalizadores, separando la supervisión bancaria de las decisiones económicas y políticas coyunturales. La supervisión bancaria debe considerarse una cuestión de Estado, lo que significa privilegiar su carácter técnico y profesional: para superar las dificultades en la materia es esencial una genuina voluntad política de llevar a cabo las transformaciones requeridas. El artículo destaca la necesidad de abordar algunos temas estructurales, como la supervisión de conglomerados financieros, la concentración excesiva del mercado a nivel nacional y regional en unas pocas instituciones, y su relación con las redes de seguridad para contener crisis sistémicas, que resultan insuficientes. En cuanto a los aspectos regulatorios, el estudio considera que es preciso mejorar la transparencia y las reglas del mercado en general, así como los mecanismos de evaluación del riesgo de cartera y de créditos relacionados, especialmente en lo que se refiere a la aplicación efectiva de las normas existentes. 


\section{Introducción}

Tradicionalmente, las recomendaciones de política para reformar el sector financiero en los países de América Latina no consideraban los aspectos relacionados con el papel que desempeña la supervisión bancaria. Esta situación cambió en el decenio de 1990, pues fueron incluidos por los expertos como una preocupación central para la estabilidad y crecimiento de la economía. Por su parte, los organismos financieros internacionales y los gobiernos centraron su atención en aspectos de supervisión bancaria como una manera de completar el conjunto de reformas que, entre otras, abarcaban la apertura comercial, la reforma tributaria, la desregulación del sector financiero y las privatizaciones. La supervisión bancaria se incorporó en su agenda en gran medida por el influjo de las crisis financieras que se desencadenaron en diversos países del mundo. ${ }^{1}$

Las crisis financieras de la década de 1990 pusieron de manifiesto que la liberalización bancaria debe ser precedida por una reforma de la regulación y de la supervisión que dote a las entidades responsables del conocimiento, las herramientas y las facultades para desempeñar una actividad de supervisión preventiva y oportuna. Esto debe ir acompañado de una estructura adecuada y una disciplina de mercado que contemple incentivos para los distintos actores. Así, los propieta- rios de los bancos deben aportar capital según el perfil de riesgo que la institución bancaria desea mantener y sufrir las consecuencias de las decisiones asociadas a una mala gestión. Los depositantes, por su parte, deben informarse acerca de la situación de las instituciones en las que mantienen sus recursos y soportar también las eventuales consecuencias adversas de sus decisiones. De la misma forma, los supervisores deben suministrar a los agentes la información necesaria, presentada de manera adecuada y oportuna, labor en la cual pueden colaborar agentes privados como los auditores externos y las empresas de clasificación de riesgo. Por último, los supervisores deben contar con las facultades necesarias y autonomía para ejercerlas, de modo que puedan actuar de manera oportuna y proporcional a las situaciones que enfrenten.

Este trabajo analiza los problemas de supervisión bancaria en América Latina. En la sección II siguiente se examinan las reformas emprendidas en la banca latinoamericana en los años noventa. En la sección III se pasa revista a los principales efectos de la liberalización bancaria en la región. En la sección IV se reseñan los problemas actuales de los sistemas de supervisión latinoamericanos y en la sección $\mathrm{V}$, por último, se presentan las principales conclusiones.

\section{II}

\section{Reformas del sistema bancario}

En América Latina, la reforma del sector financiero efectuada en los años noventa difiere de un país a otro. Así, algunos países optaron por reformas legales de fondo: Chile, México, El Salvador, Bolivia, Venezuela, Ecuador, Honduras, Paraguay, Perú y Panamá.

\footnotetext{
${ }^{1}$ Es sorprendente la ausencia de esta dimensión en las recomendaciones de política a la luz de la experiencia de países como Chile, que frecuentemente se señalaban como ejemplos de reformas, ya que la crisis que vivió el sector en 1982 fue extremadamente costosa, y se originó en la clásica combinación de políticas macroeconómicas inadecuadas y una muy deficiente supervisión bancaria (Marshall, 1991; Edwards, 1995; Ffrench-Davis, 1999).
}

Otros se inclinaron por reformas parciales que, sin embargo, significaron importantes cambios: Colombia y Costa Rica. Y otros países, por último, sólo modificaron determinados aspectos de la legislación, pero con un impacto importante: Argentina, Guatemala y Uruguay. Brasil, por su parte, produjo un cambio significativo en su mercado sin introducir modificaciones legales (Aguirre, 1998).

A pesar de estas diferencias, se perciben claras regularidades en las reformas emprendidas en la mayor parte de la región. Así, se observa una reducción de la participación estatal en los sistemas bancarios de los principales países. En Argentina, por ejemplo, entre 
1990 y 1996 el número de bancos estatales disminuyó de 36 a 20 (Leipziger, 1999). Asimismo, en Brasil se emprendió un proceso de reestructuración de la mayor parte de los bancos estatales, en el cual se ha considerado su privatización.

Otro aspecto sobresaliente ha sido el incremento de la participación extranjera en el sector. En Brasil, por ejemplo, a principios de 1999 un $20 \%$ de los activos del sistema bancario estaban en manos extranjeras, siendo que a mediados de los años ochenta lo estaba casi el 5\%. En Argentina las cifras son igualmente importantes: en efecto, el número de bancos extranjeros pasó de $14 \%$ a $19 \%$ del total de las instituciones bancarias y, lo que es mucho más significativo, en 1999 la participación de los bancos extranjeros en el total de colocaciones alcanzó a un 25\%; por otra parte, actualmente cuatro de los 10 principales bancos del país son extranjeros.

Uno de los principales propósitos de las reformas fue la ampliación del ámbito de negocios de las instituciones bancarias. Así, en todos los países se procuró ampliar la gama de los negocios que pueden desarrollar los bancos en su calidad de intermediarios financieros, para abarcar operaciones de factoraje, leasing y otros servicios financieros que fueron directamente incorporados a las actividades permitidas de los bancos. Asimismo, se facilitó la participación de las instituciones bancarias en actividades relacionadas con los mercados de valores, en particular el corretaje de valores, los seguros (underwriting) y la administración de fondos. En general, las instituciones bancarias no llevan a cabo directamente la actividad aseguradora, aunque en algunos casos se les ha permitido la comercialización de seguros, pero no en forma directa.

Sin embargo, cabe destacar que existen marcadas diferencias en la forma jurídica por la cual los bancos pueden incursionar en nuevas actividades. En algunos casos son ellos los que desarrollan directamente tales actividades y en otros pueden llevarlas a cabo a través de sociedades filiales u otro tipo de figuras legales. ${ }^{2}$

Además de la expansión de las actividades bancarias derivada de las reformas a los sistemas finan-

\footnotetext{
2 Véase un análisis más detallado en Aguirre (1998). Este autor anota, por ejemplo, que en una muestra de 17 países, los bancos podían prestar servicios de leasing financiero de manera directa en el $70 \%$ de los casos y de manera indirecta en el $24 \%$ de ellos. Por otra parte, en el $65 \%$ de los casos pueden prestar servicios de aseguramiento de manera directa y en un $29 \%$ sólo mediante una sociedad filial.
}

cieros, durante los años noventa hubo en la región una reducción drástica y sistemática de la intervención estatal en el sistema bancario, lo que ha recibido usualmente el nombre de "desregulación". En todos los países se observó una liberalización de los controles sobre las tasas de interés (normalmente tanto activas como pasivas), los requisitos de encaje y las decisiones de asignación de créditos. Esto sin perjuicio de que algunos países mantuviesen en algunos casos subsidios para ciertos créditos de fomento.

Sin embargo, la reducción de los altos requisitos de encaje que prevalecían en la mayor parte de los países de la región ha tenido una evolución dispar; estos requisitos han disminuido en muchos países, pero las rebajas han sido modestas en un número importante de ellos.

Un sistema bancario sano se fundamenta, entre otras cosas, en dos pilares básicos (cuadro 1). El primero es el conjunto de condiciones de operación del mercado: es decir, si existen restricciones a lo que los bancos pueden hacer y a la forma de hacerlo. El segundo es la calidad de la supervisión bancaria. Es importante entonces avanzar en el fortalecimiento de la supervisión bancaria antes de que se produzca la apertura, pues de lo contrario es muy posible que el proceso desemboque en una crisis del sector. Además, ese fortalecimiento es una condición necesaria para abordar la continua ampliación del ámbito de los negocios bancarios (Goldstein y Turner, 1996).

Es interesante observar lo que ocurrió con la supervisión bancaria al momento de realizar las reformas de las legislaciones en este sector. ${ }^{3}$ En Argentina, El Salvador, Nicaragua, Panamá, Perú y Uruguay las modificaciones en el sector bancario fueron acompañadas por el inicio de reformas importantes en las actividades de supervisión. En Bolivia, Colombia, Costa Rica, Ecuador, Guatemala y Honduras hubo cambios en los sistemas bancarios sin una reforma de igual magnitud en la supervisión. ${ }^{4}$

En un tercer grupo de países - Brasil, México y Venezuela - no hubo modificaciones de la legislación

\footnotetext{
${ }^{3}$ La evaluación de si hubo o no modificaciones sustantivas en los instrumentos y métodos de supervisión puede ser en algunos casos subjetiva. Se ha optado, sin embargo, por recurrir a la información que contiene el trabajo de Lora (1998), pues corresponde a una evaluación general de las reformas en América Latina y el Caribe. ${ }^{4}$ De acuerdo con la información de Lora (1998) en Bolivia, Ecuador y Guatemala hubo algunos avances. En Colombia la supervisión bancaria era buena antes de la modificación de 1990 y en Costa Rica no hubo modificaciones.
} 


\begin{tabular}{|c|c|c|c|}
\hline & & \multicolumn{2}{|c|}{ Fortalecimiento de la supervisión } \\
\hline & & Sí & No \\
\hline \multirow{2}{*}{$\begin{array}{l}\text { Reforma bancaria } \\
\text { en el decenio de } 1990\end{array}$} & Sí & $\begin{array}{l}\text { Argentina (1992), El Salvador (1990), } \\
\text { Nicaragua (1990), Panamá (1998), } \\
\text { Perú (1990), Uruguay (1985), }\end{array}$ & $\begin{array}{l}\text { Bolivia (1993), Colombia (1990), Costa Rica } \\
\text { (1988), Ecuador (1992), Guatemala (1991), } \\
\text { Honduras (1991). }\end{array}$ \\
\hline & No & Chile (1986 y 1989). & $\begin{array}{l}\text { Brasil (1988), México (1989), Paraguay } \\
\text { (1988), Venezuela (1989). }\end{array}$ \\
\hline
\end{tabular}

Fuente: elaborado sobre la base de Lora (1998) y Aguirre (1998).

a En base a la información de Lora (1998) y Aguirre (1998), hemos optado por clasificar si hubo o no un fortalecimiento de las funciones de supervisión junto con las reformas bancarias, cuando las hubo. Los casos en que hubo mejoras modestas se consideran "no reformados". En este sentido, no se hace un juicio sobre la calidad de la supervisión antes de las reformas, sino sólo si hubo o no un fortalecimiento paralelo a las reformas legales que desregularon el sector.

bancaria ni de la supervisión, pero sí se efectuó una desregulación del sector, eliminando los controles sobre las tasas de interés, los encajes y la orientación de los créditos. Además, se permitió el acceso de proveedores extranjeros a los mercados locales. Así, por ejemplo, a partir de 1988 Brasil autorizó el acceso de nuevos proveedores, tanto nacionales como extranjeros, y emprendió la privatización de varios bancos estatales. Asimismo, México comenzó en 1989 la privatización de los bancos que fueron nacionalizados a raíz de la crisis de 1982; en este caso la desregulación se vio impulsada también por las negociaciones del Tratado de Libre Comercio (TLC) de América del Norte, cuyo capítulo sobre servicios financieros significó una apertura graduada del mercado mexicano en favor de los proveedores de servicios financieros de los países miembros. Sin embargo, estas modificaciones no estuvieron acompañadas de un fortalecimiento de la supervisión bancaria.

Un caso aislado es el de Chile, país que modificó su legislación bancaria a mediados del decenio de 1980, siendo los aspectos centrales de la reforma la corrección de las deficiencias de supervisión que llevaron a la crisis financiera de 1982 y a la ampliación de los negocios. En 1989 se efectuó una segunda modificación orientada especialmente a cambiar los términos y condiciones en que se había pactado la llamada "deuda subordinada" que mantenían los principales bancos con el Banco Central y que correspondía a la adquisición de la cartera mala que debió realizar el instituto emisor como parte de la operación de rescate de la crisis. Posteriormente, en 1997, se llevó a cabo una amplia reforma del sector, que combinó la apertu- ra de la actividad bancaria a nuevos negocios y su internacionalización, con el reforzamiento de los mecanismos de supervisión.

Resulta interesante analizar si las reformas de la supervisión bancaria en la región ocurrieron antes del proceso de desregulación del sector o durante ese proceso, y si eso tuvo o no consecuencias posteriores. En el cuadro 2 hemos clasificado los países de América Latina aplicando dos criterios: si sufrieron algún tipo de crisis bancaria o sus sistemas financieros estuvieron bajo una fuerte presión que no llegó a convertirse en crisis bancaria, y si fortalecieron o no la supervisión del sector bancario. ${ }^{5}$

Como se observa en el cuadro 2, sólo en Argentina se registró una crisis posterior a reformas acompañadas del fortalecimiento de la supervisión bancaria. Esta crisis tuvo su origen en una perturbación externa, pero se agravó por la debilidad de la supervisión en un área clave: los bancos estatales. Tres aspectos vinculados explican la gravedad de la crisis. En primer lugar, la cartera vencida de los bancos provinciales alcanzaba a cerca de un $40 \%$. Segundo, los bancos comerciales habían prestado sumas importantes a bancos provinciales que no se encontraban en una buena posición financiera; estos últimos y sus operaciones eran difíciles de supervisar por consideraciones de

\footnotetext{
${ }^{5}$ El cuadro no pretende establecer una causalidad. Como señalamos a lo largo de este artículo, las crisis bancarias tienen diversos orígenes, entre los que cabe destacar las perturbaciones macroeconómicas. Sin embargo, la menor o mayor calidad de la supervisión bancaria es clave al momento de explicar el origen de una crisis o bien su agravamiento.
} 


\begin{tabular}{|c|c|c|c|}
\hline & & \multicolumn{2}{|c|}{ Fortalecimiento de la supervisión junto con las reformas } \\
\hline & & Sí & No \\
\hline \multirow{2}{*}{$\begin{array}{l}\text { Crisis o problemas } \\
\text { significativos bancarios } \\
\text { posteriores a las }^{\text {reformas }}{ }^{\text {a }}\end{array}$} & Sí & Argentina (1995). & $\begin{array}{l}\text { Bolivia (1994), Brasil (1994), Colombia } \\
\text { (1998), Costa Rica (1994), Ecuador (1995), } \\
\text { México (1994), Paraguay (1995), } \\
\text { Venezuela (1994). }\end{array}$ \\
\hline & No & $\begin{array}{l}\text { Chile, El Salvador, Nicaragua, Perú, } \\
\text { Uruguay. }\end{array}$ & \\
\hline
\end{tabular}

Fuente: Lora (1998) y Frydl (1999).

a Se consideran crisis bancarias los casos en que existen corridas, cambios bruscos en las carteras, cierre de bancos o intervención oficial. Se consideran problemas significativos los casos en que existen deficiencias que no alcanzan a ser crisis, pero ponen en riesgo la estabilidad e integridad del sistema. Entre paréntesis figura el año de inicio de la crisis.

carácter político. Y tercero, también contribuyeron a agravar la crisis las restricciones de política derivadas del régimen de cambio (Leipziger, 1999).

Se observa en el cuadro 2 que aquellos países que fortalecieron la supervisión bancaria durante el proceso de reformas no sufrieron crisis de carácter sistémico ni problemas serios. Esto no significa que no existiesen episodios aislados que afectaran severamente a bancos individuales, como sucedió en Perú a comienzos de 1999, sino que ellos fueron manejados adecuadamente, recurriendo incluso a la liquidación de las instituciones con problemas y dando así el supervisor una señal adecuada.

Los casos de México y Brasil son particularmente importantes por el peso de estos países en la región. En el primero se dio una combinación de factores que explican la ocurrencia de una crisis bancaria, entre los cuales destaca el manejo de la política macroeconómica de estabilización, especialmente del tipo de cambio. Sin embargo, existieron también factores asociados a las políticas que se aplicaban en el sector financiero y en la supervisión, entre las cuales resaltaban particularmente la rápida creación de bancos luego del proceso de privatizaciones que tuvo lugar a partir de 1989 y la insuficiente evaluación de la capacidad patrimonial de los adquirentes. Hubo además un auge de créditos, especialmente de consumo, sin que las instituciones bancarias aplicaran una adecuada política de análisis del riesgo crediticio y sin que la entidad supervisora previera las consecuencias del fenómeno.

Brasil, por su parte, también vio crecer con rapidez el número de instituciones de crédito, de 111 en 1988 a 214 en 1994, cuando se declaró la crisis. Sólo en 1989 se otorgaron 73 nuevas licencias. Según Bydalek (1999), eran varias las debilidades que presentaba el sistema bancario brasileño al momento de iniciarse la crisis. Entre ellas cabe mencionar la falta de transparencia de la información disponible: por ejemplo, no existía más información individual sobre los bancos que la que éstos publicaban en sus balances. Asimismo, la legislación mostraba numerosos vacíos y el mecanismo para ponerla en vigor era débil, especialmente en lo que tocaba a las autoridades de supervisión, lo que alentaba un comportamiento arriesgado por parte de los administradores y dueños. $\mathrm{Al}$ igual que en el caso de México, la historia inflacionaria de Brasil había inhibido la creación de una cultura de crédito que permitiera un adecuado análisis del riesgo. Por último, la continua movilidad de los principales funcionarios encargados de la política monetaria y de la supervisión creaba un grave problema de estabilidad. Lo mismo que en Brasil, en el caso de la crisis mexicana quedó en evidencia la falta de oportunidad y calidad de la información contable de los bancos que estaba disponible.

En Colombia, el proceso de reforma incluyó dos modificaciones legales, en 1990 y 1993, que apuntaban a superar las debilidades registradas en el sector bancario como consecuencia de la represión financiera (véase Steiner, Barajas y Salazar, 1998). En este contexto, se facilitó el acceso de nuevos operadores y fueron modificadas las reglas sobre fusión, adquisición y liquidación de bancos. Asimismo, se liberalizó el acceso de proveedores extranjeros. Entre 1991 y 1996 el sector público disminuyó su participación en los activos bancarios desde un 55\% a un 20\% del total 
$\mathrm{y}$, pese a haberse facilitado el acceso de proveedores extranjeros, la participación de éstos sólo aumentó ligeramente: de $7.6 \%$ a $9.7 \%$ del total de activos.

En Perú se observa una evolución similar en cuanto a reducción de la participación del sector público en el sistema bancario. En 1990 la banca comercial elevó su participación en el total de depósitos del sector bancario de $55 \%$ a $87 \%$, en tanto que el sector público diminuyó la suya a un $12 \%$ y la banca de fomento desapareció (Rojas, 1998).

\section{III}

\section{Efectos de la liberalización en la actividad bancaria}

Al evaluar el resultado de las reformas en el sector financiero, debe tenerse en cuenta que la segunda mitad del decenio de 1990 fue muy inestable, específicamente a partir de las crisis del "tequila" primero, la crisis asiática después y finalmente la crisis rusa, lo que evidentemente repercutió en la trayectoria de las principales variables.

Por otra parte, la profundidad del sector bancario (medida como la razón entre el M2 y el PIB) se incrementó entre 1990 y 1999: así, por ejemplo, en Bolivia pasó de $24.5 \%$ a $49 \%$, en Brasil de $25 \%$ a $31 \%$ y en Perú de $22 \%$ a $31 \%$. Mayor aun resulta el aumento si se comparan los años 1980 y 1999: en Brasil la cifra pasa de un $12 \%$ a un $31 \%$, en Chile de un $26 \%$ a un $51 \%$, en Argentina de $25 \%$ a $31 \%$ y en México permanece prácticamente estancada (gráfico 1).

$\mathrm{Al}$ analizar los indicadores financieros se observa que la calidad de la cartera ha evolucionado de manera diversa en la región (cuadro 3). ${ }^{6}$ En algunos países ha mejorado y en otros empeorado. Cabe destacar que un deterioro del índice de cartera vencida puede estar reflejando distintas cosas: por ejemplo, problemas macroeconómicos que afectan la capacidad de pago de los deudores, o bien reglas más estrictas de supervisión establecidas por las entidades reguladoras, lo que significa un índice más realista y no necesariamente un deterioro de la cartera. Así sucedió en México con posterioridad a la crisis "tequila". En cambio, en algunos casos un mejoramiento del índice debe ser mirado con cautela. Ecuador, por ejemplo, exhibió en 1998 un índice significativamente mejor que el

\footnotetext{
${ }^{6}$ Los autores agradecen los antecedentes proporcionados por Raúl Romero, de la Superintendencia de Bancos e Instituciones Financieras de Chile, para la elaboración de este cuadro.
}

promedio del decenio de 1980: sin embargo, la crisis que vivió en 1999 deja en claro que aquél no estaba reflejando de manera genuina la situación de cartera vencida del sistema.

El mejoramiento de la relación entre provisiones y cartera vencida que se observa en la mayor parte de los países indica que los sistemas han buscado contar con los recursos necesarios para enfrentar las posibles pérdidas asociadas al riesgo de la cartera de los bancos. Aunque se observan mejoras, todavía se requieren avances en algunos países para lograr que la cartera vencida esté plenamente cubierta por las provisiones.

En materia de rentabilidad, las cifras del cuadro 3 muestran una realidad diversa en los distintos países de la región. En efecto, en algunos de ellos la rentabilidad a fines del decenio de 1990 es claramente mejor que el promedio observado en el de 1980. En otros, sin embargo, exhibe un evidente deterioro (aunque debe tenerse en cuenta que las cifras muestran la situación en el año de la crisis asiática).

En cuanto a los niveles de capital que registran los sistemas, existe una clara tendencia al fortalecimiento de la relación entre capital y reservas, por un lado, y activos, por otro, lo que refuerza el efecto favorable que ha tenido en la solvencia la mayor cobertura de la cartera vencida con provisiones. Esto es un reflejo del proceso de reestructuración que se vivió en la mayoría de los países en que la privatización de las instituciones, las fusiones y las adquisiciones que se dieron en la mayor parte de los mercados, resultó en sistemas bancarios más capitalizados. De igual manera, luego de la entrada en vigor de las exigencias de capital recomendadas por el Comité de Basilea en 1988, ha surgido una especial preocupación por el respaldo patrimonial de los bancos, y el estándar originalmente 
GRAFICO 1

América Latina: Profundidad bancaria, 1980-1999

$(\text { M2 como porcentaje del PIB })^{\mathrm{a}}$

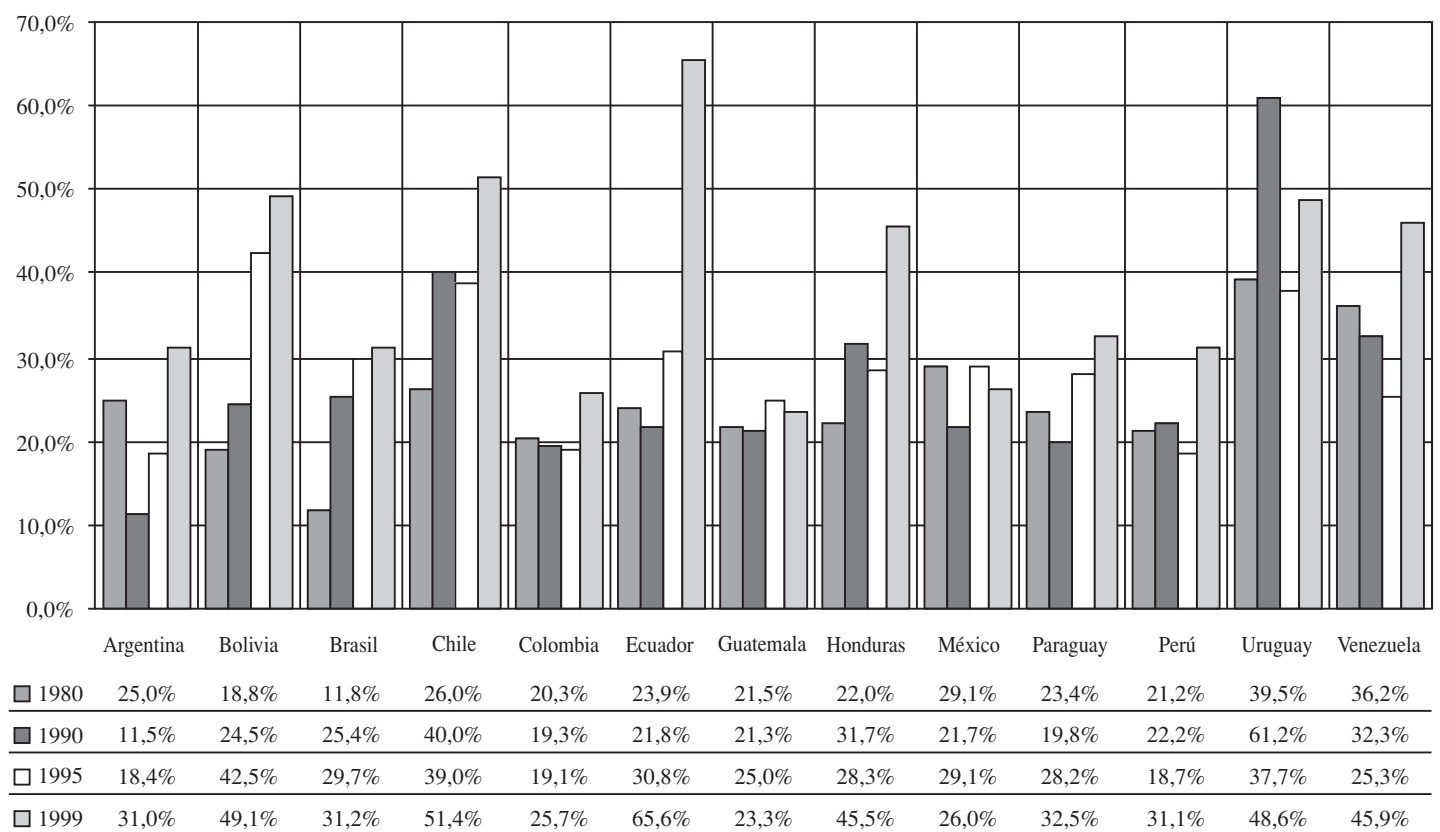

Fuente: FMI (varios años).

a El M2 corresponde a la suma de las líneas 34 y 35 de los cuadros de la fuente citada. Las cifras de Brasil y Ecuador corresponden a 1998.

CUADRO 3

América Latina: Principales indicadores del sector bancario, 1980-1999a

(Porcentajes)

\begin{tabular}{|c|c|c|c|c|c|c|c|c|}
\hline \multirow[t]{2}{*}{ País } & \multicolumn{2}{|c|}{$\begin{array}{c}\text { Cartera vencida / } \\
\text { colocaciones }\end{array}$} & \multicolumn{2}{|c|}{$\begin{array}{l}\text { Provisiones / } \\
\text { cartera vencida }\end{array}$} & \multicolumn{2}{|c|}{ Rentabilidad } & \multicolumn{2}{|c|}{$\begin{array}{c}\text { Capital y reservas / } \\
\text { activos }\end{array}$} \\
\hline & $1980-87$ & 1998 & $1980-87$ & 1998 & $1980-87$ & 1998 & $1980-87$ & 1998 \\
\hline Argentina & 25.2 & 10.4 & 19.9 & 65.2 & 28.7 & 2.3 & 10.1 & 11.5 \\
\hline Bolivia & 20.6 & 4.5 & 44.4 & 57.9 & -2.5 & 7.8 & 13.0 & 8.5 \\
\hline Brasil & 1.1 & 7.4 & 87.7 & 113.3 & 62.3 & 6.9 & 7.4 & 8.9 \\
\hline Chile & 4.5 & 1.6 & 136.4 & 133.9 & 4.3 & 11.7 & 5.8 & 6.4 \\
\hline Colombia & 7.4 & 9.9 & 70.6 & 38.1 & -14.6 & 11.6 & 5.6 & 10.5 \\
\hline Ecuador & 13.4 & 5.3 & $\ldots$ & 138.5 & 20.7 & 7.7 & 5.5 & 15.2 \\
\hline Guatemala & $\ldots$ & 4.4 & $\ldots$ & 46.5 & 8.2 & 13.3 & 8.2 & 8.1 \\
\hline Honduras & 19.1 & 4.8 & 29.8 & 48.9 & 3.5 & 17.3 & 7.1 & 9.9 \\
\hline México & 1.6 & 9.1 & 60.0 & 67.4 & 40.3 & 6.3 & 2.0 & 8.8 \\
\hline Perú & 3.7 & 6.9 & 148.8 & 92.0 & 25.5 & 9.5 & 6.5 & 9.0 \\
\hline Uruguay & 26.0 & 9.7 & 4.8 & 68.2 & -0.3 & 5.6 & 6.2 & 15.6 \\
\hline Venezuela & 10.8 & 4.2 & $\ldots$ & 150.3 & 10.8 & 0.05 & 4.8 & 13.8 \\
\hline
\end{tabular}

Fuente: Morris, Dorfman, Ortiz y Franco (1990); Latin Finance (varios años).

a Las cifras no son necesariamente comparables debido a modificaciones en las definiciones empleadas por los países. 
diseñado para el Grupo de los Diez se ha transformado en un requisito de general utilización.

Si los sistemas de supervisión cuentan actualmente con los elementos esenciales para realizar una supervisión efectiva, como afirman los propios reguladores, cabe preguntarse por qué la mayoría de los países ha registrado algún tipo de crisis o problema serio en el sector. Del análisis de las legislaciones comparadas, y en opinión de los propios supervisores, se desprende que hoy existen los instrumentos necesarios para llevar a cabo una supervisión adecuada. Teóricamente, los supervisores tienen facultades para autorizar el funcionamiento de nuevos bancos, establecer y evaluar los requisitos que deben cumplir los accionis- tas y/o administradores de las instituciones bancarias, aprobar traspasos de propiedad (salvo en Argentina y Paraguay) y efectuar controles de estructura. Asimismo, en la mayoría de los países de la región hay límites a los créditos en general y a los créditos relacionados en particular. En el $70 \%$ de los países se utiliza información consolidada; en todos se controlan la solvencia, la calidad de los activos, la liquidez y las posiciones en divisas, y en el $70 \%$ se supervisan las operaciones fuera del balance (Livacic y Sáez, 2000).

La razón de la aparente contradicción señalada radica en que, a pesar de los progresos alcanzados, aún falta abordar una importante agenda de trabajo en el ámbito de la supervisión.

\section{IV}

\section{Consideraciones y recomendaciones de política}

Como se reseñó en la sección anterior, en América Latina el decenio de 1990 se caracterizó en general por un avance significativo en la legislación y la regulación bancaria, por cierto con diferencias de ritmo y profundidad entre los distintos países considerados. Sin embargo, existe aún una serie de dificultades que deben ser abordadas para ir superando las deficiencias que todavía subsisten o bien las que han surgido del propio proceso de reformas y de los cambios experimentados a nivel global por la economía, la industria financiera y la tecnología.

Para facilitar su análisis hemos agrupado esas tareas pendientes en torno a cuatro temas: estructura y funcionamiento del mercado; autonomía y facultades de los órganos supervisores; mejoramiento de la regulación, y mejoramiento de la supervisión.

\section{Estructura y funcionamiento del mercado}

En el decenio de 1990 se observó en la mayor parte de la región la tendencia a que el número de bancos disminuyera; en términos generales esta evolución debiera considerarse favorable, ya que inicialmente había un gran número de instituciones muy pequeñas, lo que suele traer consigo ineficiencias - es decir, un alto costo de intermediación - y la menor solvencia y mayor inestabilidad de instituciones bancarias muy pequeñas.
Muchos son los factores que explican la reducción del número de bancos. Primero, las crisis bancarias que siguieron ocurriendo en la región en el decenio trajeron aparejada la salida de algunos bancos del mercado, por quiebra o por haber procedido las autoridades a liquidarlas. Segundo, la región vivió en esa década el proceso global de adquisiciones, absorciones y fusiones que ha caracterizado también a los sistemas bancarios de los Estados Unidos, Europa y Japón. Aun más, en buena medida el proceso de consolidación bancaria en el continente es una consecuencia de fusiones que han ocurrido entre dos o más instituciones en los mercados desarrollados. Tercero, tras la consolidación de la industria bancaria en América Latina se hallan los procesos de estabilización macroeconómica que tuvieron lugar en la región (como el Plan Real de Brasil en 1994, que redujo fuertemente la inflación y con ello cambió la naturaleza del negocio bancario en ese país, pues antes de la estabilización de precios éste consistía en una mera recaudación del impuesto-inflación). Por último, cabe destacar en especial el esfuerzo desplegado por algunas autoridades supervisoras nacionales que, empeñadas en lograr entidades más eficientes y con mayor solvencia, han "inducido" en sus jurisdicciones nacionales un proceso de consolidación de la industria que se ha visto facilitado por la ola internacional de fusiones y adquisiciones, así como por el interés de los accionistas extranjeros por ingresar al 
mercado. Este proceso se agudizó en la segunda mitad de los años noventa y ha tenido especial vigor en Argentina, Brasil, Chile, México y Venezuela.

En este contexto - un número menor de bancos de mayor tamaño- y si se diera una evolución de tipo pendular, podrían surgir algunos riesgos como el de una excesiva concentración de la industria. Después de la última fusión bancaria autorizada en México (BBVABanamex), el banco más grande en ese país tiene una participación de mercado superior al 30\%; una situación similar podría producirse en Chile (SantanderSantiago) y existe hace varios años en Perú (Banco del Comercio). El mismo proceso se ha iniciado en Brasil, Venezuela y Colombia, sin alcanzar aún la magnitud que tiene en México. Lo que preocupa de una alta concentración es su eventual impacto negativo en la competencia y en la estabilidad del sistema financiero (especialmente si hay entidades consideradas "demasiado grandes para fracasar"), así como la excesiva influencia sobre ciertas políticas macroeconómicas que pudiera tener una institución de gran tamaño.

Otro fenómeno significativo que modificó la estructura de la industria bancaria latinoamericana en el decenio de 1990 fue el gran aumento de la participación extranjera en la propiedad de los bancos nacionales. De este fenómeno, inserto en la globalización bancaria mundial, han escapado muy pocos países; lo hicieron particularmente aquéllos en los cuales aún existían limitaciones legales para el ingreso de bancos extranjeros al mercado (México hasta 1995 y Ecuador hasta el 2000).

La presencia de la banca extranjera en los mercados internos contribuye a dinamizar la competencia, incorporar nuevas tecnologías y productos, introducir formas eficientes de gestión y reforzar la base de capital de los sistemas bancarios. Es más, en varias de las crisis sistémicas o episodios de fuertes inestabilidades financieras, la banca extranjera radicada en el país ha sido un elemento estabilizador, por el traslado de los depósitos desde los bancos nacionales a los extranjeros situados en el país (efecto fly to quality), que son percibidos por el público como más seguros (casos de Paraguay en 1995, Argentina en ese mismo año y Chile en 1982). Esto redujo significativamente la salida de capitales.

Sin embargo, cabe puntualizar que el proceso de extranjerización de la propiedad bancaria en América Latina está concentrado en muy pocas entidades, las que suelen tener además una alta participación de mercado en varios países de la región. Si se produjera la quiebra o inestabilidad de alguno de esos grandes bancos, que tienen presencia a nivel global, se podría producir una crisis bancaria regional o mundial a una escala sin precedentes. En la actualidad, las legislaciones nacionales y la arquitectura de la "red de seguridad" internacional no estaría en condiciones de abordar una situación de esas características, lo que constituye una réplica del fenómeno que ya ocurrió a nivel interno, cuando la desregulación no fue precedida por un reforzamiento de los mecanismos para prevenir las crisis (supervisión real de seguridad).

Por otra parte, aún hay en la región países en los cuales los bancos estatales tienen una gran participación de mercado: en Costa Rica y Uruguay, por ejemplo, la cuota de mercado de los bancos estatales es del orden del 50\%, y en Argentina y Brasil, aun después de los avances en la privatización de algunas entidades provinciales o estaduales, los dos bancos más grandes del mercado siguen siendo bancos públicos.

No obstante lo anterior, conviene destacar que en el decenio de 1990 no hubo en América Latina estatizaciones masivas de bancos como las ocurridas en Perú y México en el decenio anterior; es más, estos dos países reprivatizaron en los años noventa todas las instituciones estatizadas en los ochenta. Hay que resaltar también que, en general, las intervenciones de instituciones bancarias ante las crisis del decenio de 1990 no desembocaron en nacionalizaciones, sino que se tradujeron en administraciones transitorias por algún organismo estatal.

Aunque no existe consenso entre los especialistas sobre cuál debe ser el papel del Estado en la propiedad bancaria, la existencia de bancos estatales ha sido justificada por la función social y de fomento que ellos desempeñarían. Está claro que una alta participación estatal en el mercado bancario trae dificultades, como el desplazamiento de la banca privada, la injerencia política en la asignación de créditos, la mayor dificultad de obtener entidades eficientes y la entrega de subsidios mal focalizados. Desde el punto de vista de la supervisión y regulación bancarias, se observa en varios casos que las instituciones financieras de propiedad estatal son objeto de menores exigencias patrimoniales y, en la práctica, no siempre pueden ser supervigiladas con la misma severidad que las privadas. En todo caso, debe asumirse en plenitud que la participación estatal en la actividad bancaria no puede basarse en un estatuto de supervisión que sea discriminatorio y menos riguroso.

Por último, un problema estructural de la mayor importancia que no ha sido resuelto en América 
Latina es la dificultad para acceder al financiamiento que afecta a una gran cantidad de empresarios pequeños y microempresarios. La expansión de la actividad bancaria derivada de la desregulación de los mercados financieros no ha alcanzado aún a estos segmentos, debido en parte a su carácter de informal, al sesgo en las políticas crediticias y a veces en la regulación que privilegia la obtención de garantías, así como al mayor costo y alto riesgo que suelen presentar estas operaciones por montos más bajos. Una situación similar se presenta respecto a las necesidades de financiamiento de las personas.

La dificultad de acceso de las pequeñas empresas limita significativamente su capacidad competitiva y se transforma en un freno al desarrollo, toda vez que estos sectores hacen uso más intensivo de mano de obra y son los principales generadores de empleo. Por otra parte, la marginación de vastos sectores del acceso al financiamiento constituye una barrera a la apertura de oportunidades y, por lo tanto, un obstáculo para una efectiva democratización de la sociedad.

\section{Autonomía y facultades de los órganos super- visores bancarios}

En los últimos diez años la supervisión bancaria ha evolucionado de manera rápida y dinámica para adaptarse a las nuevas realidades del mercado y a las nuevas disposiciones legales y administrativas que permitieron una mayor actividad bancaria.

Una constante en el proceso de modificaciones legales latinoamericanas en el decenio de 1990 fue la de integrar en las reformas financieras el mejoramiento de los órganos de supervisión bancaria. Así, junto con buscarse la ampliación de las actividades bancarias y disminuir las restricciones al funcionamiento, usualmente se persigue dotar a las instituciones supervisoras, superintendencias o comisiones bancarias de mayores atribuciones legales y de más recursos humanos y materiales para cumplir con su tarea. Tanto los organismos multilaterales como los propios gobiernos dedican una cantidad creciente de recursos a este fin.

El ritmo de crecimiento de la actividad bancaria y la ampliación del ámbito de acción de los bancos han sido vertiginosos, lo que unido a algunas crisis bancarias ha exigido de los entes supervisores una gran capacidad de adaptación y respuesta, ya que de manera simultánea se ha modificado la legislación, se ha abordado la situación de los bancos en problemas y se han renovado la normativa y los métodos de supervisión.
Entre los avances pendientes está el otorgar a los órganos supervisores una real y efectiva autonomía, con dimensiones políticas, jurídicas, económicas y operacionales. $^{7}$

En lo político, quizás el problema mayor sea la alta dependencia del poder político que, en general y más allá de lo que establece la legislación, tienen los jefes superiores de las entidades supervisoras. En el contexto de sistemas bancarios liberalizados, en los cuales las decisiones son tomadas por los bancos privados sobre la base de criterios de mercado, la supervisión es una función pública eminentemente técnica que resguarda de algunos riesgos, especialmente el del costo fiscal de las insolvencias bancarias.

Una de las manifestaciones de la injerencia política en la supervisión bancaria es la alta rotación de superintendentes, los que sólo excepcionalmente extienden su mandato al mismo plazo del período presidencial y más difícilmente aún se mantienen en sus cargos frente a un cambio de gobierno. En promedio, en la región la permanencia en el cargo de los superintendentes durante el decenio de 1990 fue cercana a los dos años. Esto, unido al bajo nivel de desarrollo de las instituciones pertinentes que en general presenta América Latina, lleva a que al sustituir al superintendente se reemplace también una parte importante del personal técnico superior, con lo cual resulta muy difícil conservar y consolidar los avances alcanzados en cada administración.

Un segundo aspecto que ha retardado un desarrollo más dinámico de los organismos supervisores es la dificultad de contar con recursos humanos capacitados para adaptarse, al ritmo y con la profundidad requeridos, a las cambiantes condiciones del entorno. La sobredotación de personal que presentan algunos de esos organismos, junto a la inamovilidad funcionaria, las remuneraciones insuficientes, la injerencia de criterios políticos en las designaciones y la herencia de funcionarios más antiguos, en general carentes de formación universitaria y preparados sólo para una supervisión de carácter formal, son los principales escollos que todavía quedan por superar en un gran número de países para profesionalizar con más rapidez la supervisión bancaria y ponerla a tono con las exigencias del momento y del futuro.

\footnotetext{
${ }^{7}$ La autonomía de los organismos de supervisión bancaria debe ser entendida como un tema en sí mismo, más allá de si ellos dependen o no del banco central. Es más, de los países considerados en este estudio sólo los miembros del Mercosur mantienen la supervisión bancaria dentro del banco central. Lo importante es darle a la función la relevancia que tiene y completarla con los recursos materiales y humanos y las facultades legales que sean necesarios.
} 
A pesar de los esfuerzos realizados por dotar a los organismos supervisores de los recursos económicos necesarios para cumplir adecuadamente con su labor, varios de ellos experimentan aún restricciones presupuestarias que limitan un buen desempeño. Al ya señalado problema de las remuneraciones, debe agregarse la necesidad de contar con los medios necesarios para entregar capacitación continua y permanente, y los medios tecnológicos y los sistemas de información indispensables para una supervisión moderna. De igual forma, cabe señalar que la autonomía política tiene como base una autonomía económica, que a su vez debe contemplar resguardos que aseguren la buena y transparente administración de los recursos (auditorías externas, contralorías, cuentas públicas de gestión, etc.). En este aspecto, mirado como evaluación del proyecto, la supervisión es rentable, ya que resulta mucho más barato para el Estado financiar una buena superintendencia que pagar la cuenta de las crisis derivadas de una insuficiente supervisión bancaria.

Por último, en lo legislativo deben darse pasos rápidos para crear formas de protección jurídica a los supervisores, de acuerdo con las recomendaciones internacionales hechas por el Comité de Basilea, de modo que ellos puedan ejercer su labor sin temor a represalias de carácter legal. Al respecto, constituye un lugar común entre los jefes superiores de los organismos de supervisión en América Latina el tener varios juicios en su contra por decisiones tomadas en el ejercicio de su cargo. Estos juicios son entablados por accionistas que reclaman haber sido tratados con arbitrariedad e innecesaria dureza, normalmente durante las crisis, o por depositantes que, después de las crisis, reclaman que la negligencia del supervisor y la falta de celo en el desempeño de sus funciones les hizo perder sus ahorros.

Junto con avanzar hacia una mayor autonomía, las superintendencias deberían estar sujetas a un mayor escrutinio público respecto del fundamento de sus principales decisiones y basar éstas en criterios conocidos por los distintos agentes involucrados, de manera de dar garantías de objetividad en el ejercicio de sus atribuciones.

\section{Mejoramiento de la regulación}

En el ámbito legislativo y regulatorio también se hicieron importantes avances en la década de 1990, sin perjuicio de lo cual existen muchas tareas pendientes que para ser implementadas requieren de destrezas técnicas, pero sobre todo de una gran voluntad política.
La tarea pendiente de mayor envergadura es la regulación de los conglomerados financieros, lo que tiene múltiples dimensiones. En la versión más divulgada entre los especialistas, la regulación de los conglomerados financieros se entiende como un cuerpo normativo que da cuenta de las actividades de un grupo económico que actúa en distintos giros financieros, abarcando áreas como banca, valores, seguros y pensiones, y que eventualmente se extiende también a los sectores de la industria y el comercio. Esta visión de la regulación de los conglomerados, que es la más amplia y completa, está ya incorporada en algunas legislaciones (como en México y El Salvador, y de alguna manera en Venezuela y Ecuador). Sin embargo, casi sin excepciones la aplicación efectiva de estas normas aún está pendiente.

Sin embargo, esa visión más global de la regulación de los conglomerados no es la única que debe preocupar en la región. Por el contrario, existen algunas deficiencias mucho más evidentes y graves en la regulación de los conglomerados, como la ausencia de regulación y supervisión amplias y consolidadas de lo que podría denominarse el subconglomerado bancario, en el que se incluyen sólo las actividades de intermediación financiera (captación y colocación de dinero). En América Latina, bajo ciertas figuras jurídicas diseñadas precisamente para eludir la regulación, existe en la práctica una serie de organismos y mecanismos a través de los cuales se efectúan —en forma paralela y vinculada con el banco- actividades bancarias que no se encuentran sometidas a fiscalización.

El mecanismo más utilizado es el de centros offshore no regulados: un banco o sus accionistas crean otro banco en un país distinto, con menores exigencias regulatorias y normalmente con exenciones tributarias, en el que contabilizan una parte de las actividades bancarias que efectúan en su país de origen. Estas entidades off-shore suelen estar protegidas por legislaciones donde el secreto bancario es muy fuerte y extendido, lo que las deja fuera del alcance de su supervisor local. Este fenómeno ha alcanzado en algunos países dimensiones muy significativas como porcentaje de la actividad bancaria local debidamente reconocida. Así, por ejemplo, en la crisis bancaria de 1994 en Venezuela (1994) y en Ecuador(1998) se reflejó que una parte significativa de la actividad bancaria estaba contabilizada en las subsidiarias off-shore. ${ }^{8}$

\footnotetext{
${ }^{8}$ En la resolución de la crisis las autoridades de esos países extendieron el seguro estatal a estas operaciones.
} 
Algo similar ocurrió con algunos de los bancos en la crisis en Paraguay (1995).

Otras fórmulas utilizadas para eludir la regulación y supervisión son las de crear entidades no reguladas o reguladas muy débilmente y que por la vía de subterfugios son separadas "artificialmente" del banco. De estas figuras la más difundida en distintos países es el fideicomiso. Estas entidades no reguladas han estado en el origen de crisis individuales de instituciones en El Salvador, Paraguay y Guatemala, sólo por citar algunos ejemplos.

En el ámbito regulatorio existen, asimismo, retrasos en la regulación de los riesgos de mercado (monedas y tasas), así como del riesgo-país y el riesgo de liquidez. De estos riesgos, el más relevante en el plazo inmediato es el de monedas, ya que de hecho una parte importante de los activos bancarios está denominada en dólares (Argentina, Perú, Venezuela y Ecuador antes de la dolarización). Sin embargo, él dependerá de la tendencia que sigan los regímenes cambiarios en la región.

Por otra parte, a medida que los mercados bancarios se sigan sofisticando y las operaciones a plazos más largos cobren mayor importancia, habrá que avanzar más en la regulación de sus riesgos inherentes (tasas y plazos).

En materia de resolución de crisis bancarias algunos países han llevado a cabo en los últimos años algunas iniciativas interesantes, cuya irradiación al resto de la región constituye una necesidad imperiosa. Lo han hecho en la misma línea del esquema seguido por la FDIC de los Estados Unidos, buscando el denominado "menor costo de resolución" de un banco en problemas. En una operación relámpago, que se efectúa normalmente en un fin de semana, el banco aproblemado se divide en un "banco bueno" y un "banco malo". El "banco bueno" (con sus correspondientes pasivos) se transfiere a terceros, normalmente a otra entidad bancaria ya existente, y sigue operando. El "banco malo" se liquida. Las pérdidas finales las absorben los accionistas y el seguro de depósitos, con lo que se obtiene además un costo menor que el de liquidar toda la institución. Iniciativas de esta índole, así como la reforma a los sistemas de seguros de depósitos para permitir manejos más flexibles y eficientes de carácter anticipatorio y no meramente curativo, son otros de los desafíos en el ámbito normativo y legal.

Finalmente, los países de la región deben mejorar significativamente la transparencia y confiabilidad de la información. Al respecto se han producido avances importantes, pero debe haber mayor progreso. Esta dimensión es central para que exista una efectiva dis- ciplina de mercado. Los agentes deben tener acceso a información relevante de manera oportuna. Sobre este punto hay que mencionar en particular las prácticas contables. Así, se debe avanzar hacia estándares de información que faciliten las comparaciones entre países y, muy especialmente, que permitan conocer con precisión y de manera fidedigna la real situación individual de los bancos.

\section{Fortalecimiento de la supervisión}

En la supervisión bancaria — vale decir, en la labor misma de verificación de la observancia efectiva de las disposiciones prudenciales- los avances en la década de 1990 fueron insuficientes ante la complejidad de la evolución de las actividades bancarias.

En todos los sistemas financieros del mundo el riesgo bancario más importante sigue siendo el crediticio. En América Latina, con un grado de sofisticación menor que los países desarrollados, el peso relativo del riesgo de crédito es aun más alto. Si bien un número creciente de países latinoamericanos ha incorporado regulaciones que dicen relación con la estimación del riesgo de crédito de acuerdo a la proyección de la capacidad de pago del deudor, en la práctica sigue siendo la morosidad — vale decir, la constatación ex post de las dificultades de pago- el procedimiento más utilizado. Cuando eso ocurre, la supervisión pierde gran parte de su carácter preventivo, transformándose más bien en la "geomensura" posterior de los problemas patrimoniales.

Algo similar ocurre con los créditos vinculados o relacionados con la propiedad. Las disposiciones legales y la regulación respectiva fueron introducidas en todos los países de la región a partir del decenio de 1980; sin embargo, con contadas excepciones, su aplicación práctica es bastante limitada, ya que existen serios problemas de información para poder detectar tales operaciones y hasta ahora los subterfugios que utilizan los gestores han superado la capacidad de supervisión. Por otra parte, las legislaciones han evitado entregar atribuciones que permitan, bajo la figura de presunciones fundadas de vinculación, una aplicación efectiva de la norma por parte de los supervisores.

El problema de los créditos vinculados o relacionados tiene varias dimensiones y aristas, pero quizás la más clara de ellas es que en casi todas las crisis bancarias de la región ha estado presente el problema de la cartera vinculada y de su baja calidad crediticia.

Cuando la cartera vinculada supera el capital pagado y reservas se erosiona una de las bases fundamen- 
tales de un sistema financiero estable, que es su solvencia, ya que se debilita el incentivo para seguir políticas de riesgo prudentes constituido por la posibilidad de que los accionistas pierdan su capital.

Las debilidades antes señaladas —en la evaluación del riesgo de la cartera y los créditos relaciona-

\section{$\mathrm{V}$}

\section{Conclusiones}

En síntesis, se puede señalar que durante los años noventa el proceso de transformación de los sistemas financieros en América Latina fue profundo. Sin embargo, las reformas adoptadas no siempre estuvieron acompañadas de un fortalecimiento de la supervisión del sector. Esto significó en varios casos una fragilidad que se hizo patente cuando las economías estuvieron sujetas a algún tipo de perturbación externa. La segunda mitad de la década de 1990 presenció un proceso de transición hacia sistemas bancarios más sólidos, basados en un adecuado equilibrio entre los incentivos del mercado y un marco regulatorio y de una supervisión preventiva.

En lo que se refiere a estructura de mercado, América Latina presenta aún algunos viejos problemas como la alta participación estatal, materia en la que, sin embargo, hay claros avances. Asimismo, han surgido nuevos problemas estructurales, como el de una concentración de mercado que podría ir más allá de lo deseable no sólo a nivel de país, sino también a escala regional, superando el alcance sólo interno de las "redes de seguridad sistémicas".

De igual forma, el rápido y dinámico proceso de desarrollo cambiario ocurrido en los años noventa en la región aún no ha llegado suficientemente a los sectores de la microempresa y pequeña empresa, ni a las personas, convirtiéndose así en una seria limitación al dos - constituyen los ejemplos más evidentes de una realidad común en la región y que dice relación con serias dificultades para la aplicación efectiva de las normas vigentes por las autoridades responsables, tanto por los problemas de autonomía descritos como por la ya mencionada carencia de recursos. crecimiento del empleo, el producto y la participación en los frutos del progreso.

Para superar la mayor parte de las deficiencias señaladas en este artículo, y en especial aquéllas que dicen relación con los problemas regulatorios, la supervisión bancaria y la autonomía de los organismos fiscalizadores en América Latina, hay un elemento trascendental, que es la voluntad política de hacer los cambios aún pendientes. Para que ésta se haga presente, se debe dejar de ver la supervisión bancaria como una parte integrante de la política económica coyuntural y como un instrumento de poder político. En cambio, la labor de supervisión bancaria debe ser asumida como una política de Estado, otorgándoles a los entes fiscalizadores los correspondientes niveles de autonomía y privilegiando su carácter técnico y profesional.

En cuanto a la regulación bancaria, la tarea de mayor envergadura que debe abordar América Latina es la regulación de los conglomerados financieros, tanto a nivel de la actividad interna de los grupos bancarios como de sus actividades transfronterizas, especialmente la desplegada en los centros off-shore.

En el terreno de la supervisión propiamente tal, aún resta profundizar el seguimiento preventivo del riesgo de crédito y mejorar el de la exposición de los créditos relacionados.
Aguirre, E. (1998): Reformas básicas de los sistemas bancarios en América Latina: Análisis, tendencias y perspectivas, en J. Norton y E. Aguirre (eds.), Sistemas bancarios latinoamericanos: reformas recientes y perspectivas, Caracas, Fundación La Casa de Bello.

Arraes, M.C. (1998): El caso de Brasil, en J. Norton y E. Aguirre (eds.), Sistemas bancarios latinoamericanos: reformas recientes y perspectivas, Caracas, Fundación La Casa de Bello.
Bydalek, P.L. (1999): Lessons from recent global bank failures: The case of Brazil, en G. Caprio y otros, Preventing Banking Crises: Lessons from Recent Global Banking Failures, Washington, D.C., Federal Reserve Bank of Chicago/Banco Mundial.

Caprio, G. y otros (1999): Preventing Banking Crises: Lessons from Recent Global Banking Failures, Washington, D.C., Federal Reserve Bank of Chicago/Banco Mundial. 
Comisión Nacional Bancaria de México/CEMLA (Centro de Estudios Monetarios Latinoamericanos) (1995): Encuesta sobre prácticas de supervisión de entidades nacionales y extratransfronterizas, CEMLA,Undécima Asamblea de la Asociación de Organismos Supervisores Bancarios de América Latina y el Caribe. Reuniones y seminarios, México, D.F.

Díaz de León, A. y M. J. Schwartz (1997): Crisis management and institutional change aimed at the prevention, en G.M. von Fürstenberg, The Banking and Financial Structure in the NAFTA Countries and Chile, Londres, Kluwer Academic Publishers.

Edwards, S. (1995): Crisis y reforma en América Latina, Buenos Aires, Emecé Editores.

FMI (Fondo Monetario Internacional) (varios años): Estadísticas financieras internacionales, Washington, D.C.

Ffrench-Davis (1999): Macroeconomía, comercio y finanzas para reformar las reformas en América Latina, Santiago de Chile, McGraw-Hill Interamericana.

Frydl, E. (1999): The length and cost of banking crises, IMF working paper, № 30, Washington, D.C., FMI, marzo.

Gavin, M. y R. Hausmann (1997): Las raíces de las crisis bancarias: el contexto macroeconómico, en R. Hausmann y L. Rojas-Suárez, Las crisis bancarias en América Latina, Washington, D.C., Banco Interamericano de Desarrollo/Fondo de Cultura Económica.

Goldstein, M. y P. Turner (1996): Banking Crises in Emerging Economies: Origins and Policy Options, Basilea, Comité de Basilea de Supervisión Bancaria.

Goldstein, M. (1998): The Asian crisis: Causes, cure, and systemic implications, Policy Analyses in International Economics, $\mathrm{N}^{\circ}$ 55, Washington D.C., Institute for International Economics (IIE), junio.

Hausmann, R. y L. Rojas-Suárez (1997): Las crisis bancarias en América Latina, Washington, D.C., Banco Interamericano de Desarrollo/Fondo de Cultura Económica.
Latin Finance (varios años): Coral Gables, Florida, Latin American Financial Publications, Inc.

Leipziger, D.M. (1999): The Argentine banking crisis: Observations and lessons, en G. Caprio y otros, Preventing Banking Crises: Lessons from Recent Global Banking Failures, Washington, D.C., Federal Reserve Bank of Chicago/Banco Mundial.

Livacic, E. y S. Sáez (2000): La supervisión bancaria en América Latina en los noventa, Temas de coyuntura, № 10, Santiago de Chile, Comisión Económica para América Latina y el Caribe (CEPAL).

Lora, E. (1998): Una década de reformas estructurales en América Latina: qué se ha reformado y cómo medirlo, Pensamiento iberoamericano, número extraordinario, Madrid, Sociedad Estatal Quinto Centenario, marzo.

Lora, E. y F. Barrera (1998): El crecimiento económico en América Latina después de una década de reformas estructurales, Pensamiento iberoamericano, número extraordinario, Madrid, Sociedad Estatal Quinto Centenario, marzo.

Marshall, E. (1991): El sistema financiero y el mercado de valores en Chile, México, D.F., Centro de Estudios Monetarios Latinoamericanos.

Morris, F., M. Dorfman, J.P. Ortiz y M. C. Franco (1990): Latin America's banking systems in the 1980's: A cross-country comparison, Discussion papers, $\mathrm{N}^{\circ} 81$, Washington, D.C., Banco Mundial, marzo.

Norton, J. y E. Aguirre (eds.) (1998): Sistemas bancarios latinoamericanos: reformas recientes y perspectivas, Caracas, Fundación La Casa de Bello.

Rojas, J. (1998): Determinantes del spread en la tasa de interés bancaria en el Perú: 1991-1996, Documento de Trabajo, № R-330, Washington, D.C., Banco Interamericano de Desarrollo (BID).

Steiner, R., A. Barajas y N. Salazar (1998): El margen de intermediación bancaria en Colombia, Documento de Trabajo, $\mathrm{N}^{\circ}$ R-325, Washington, D.C., Banco Interamericano de Desarrollo (BID).

Von Fürstenberg, G.M. (1997): The Banking and Financial Structure in the NAFTA Countries and Chile, Londres, Kluwer Academic Publishers. 